\title{
The structural modification of cassava starch using a saline water pretreatment
}

\author{
Hanny Frans SANGIAN ${ }^{1 \star}$, Richard TELLENG ${ }^{1}$, Irfan ARUAN ${ }^{1}$, Handy Indra Regain MOSEY ${ }^{1}$, \\ Gerald Hendrik TAMUNTUAN ${ }^{1}$
}

\begin{abstract}
The cassava has been modified successfully by using the saline water, which was abundantly available on the planet. The biomass was submerged in saline waters that salt concentrations were altered at $0,3.5$ percent (seawater) and 10 percent $(\mathrm{w} / \mathrm{w})$ and were kept 5 days. After recovery by washing steps, the treated solids were characterized by using XRD (X-ray diffraction), FTIR (Fourier transform infra-red), and SEM (Scanning electron microscopic). The results showed that the XRD pattern of saline water pretreatment decreased significantly. The biggest decrease of X-ray intensity occurred at around $18^{\circ}$. Meanwhile, the fingerprint of FTIR revealed the transmittance intensity of infra-red ray of saline water treated solid inclined for all wave constant numbers, suggesting that many hydrogen bonds were disconnected. Those findings also were enhanced by SEM pictures that showed the change of surface morphology of treated biomass. It was indicative that cassava structure was modified becoming more textured after employing saline water pretreatment. This work is an innovative finding to gradually substitute commercial ionic liquids that are very expensive with saline water for biomass pretreatment.
\end{abstract}

Keywords: cassava; saline water; pretreatment; amorphous structure.

Practical Application: The saline water-treated cassava can be proceeded to produce textured food, sugar, alcohol and biofuels.

\section{Introduction}

Currently, the biomass has been converted into reducing sugars and renewable biofuels, such as ethanol (Hernoux et al., 2013). Generally, the starch can be found from plants, which grow in tropical- and sub-tropical lands the following corn, tubers, cassava, wheat, sago and rice (Nafchi et al., 2012; Puncha-Arnon \& Uttapap, 2013). Actually, the raw starch biomass contents are starch itself and a small amount of cellulose, hemicellulose, and lignin (Zhang et al., 2013). The cassava starch has been investigated and attracted many scientists who developed them becoming more valuable materials, like modern food and alcohol (Souto et al., 2016; Silva et al., 2013; Gunawan et al., 2015; Pereira \& Leonel, 2014).

Investigators, who developed the starch, concentrated on its crystallinity, surface morphology and its structural modification as previously reported (Alcazàr-Alay \& Meireles, 2015). Many authors concluded that pretreatments were the most crucial step of overall processes obtaining more valuable starch. One of the works was aimed at changing the starchy crystal from well arranged- into more amorphous forms (Neelam et al., 2012).

Acids and alkaline were employed to pretreat starch that purposed to alter its crystallinity and the result showed the enzymatic hydrolysis improved significantly (Lopez et al., 2011). Another chemical treatment on residual cassava was employed to analyze the acidity and microbial growth as reported by author
(Souza et al., 2013). As the high pressure and temperature, sub- and supercritical methods have been also applied to modify the biomass structure (Manzanares et al., 2012). They investigated that the explosion method in which pressure decreased abruptly, could alter biomaterial structure and breakdown the glycosidic connections. Commercial ionic liquid, which was expensive has been also employed for starch treatment (Yakubov et al., 2015).

The chemical agents like acids, alkaline and ionic liquids, which were used on starch pretreatment generated pollution over soil and water and also were poisonous. Sub- and supercritical methods, which were performed at high pressure and temperature, were considered insecure and expensive (Sangian et al., 2015). The safety, clean and technologies for pretreatment should be developed and fullfilled conditions and standards of environmentally-friendly procedures.

The present investigation is to change the structure of cassava starch performing saline water which was abundantly available. According to intensive references study conducted, saline water has not been employed for cassava starch pretreatment for structural alteration. Procedures are as follows: biomass drying and milling, washing step and characterization. The crystallinity of treated solids and native cassava are measured using XRD, SEM, and FTIR. 


\section{Materials and methods}

The starch (cassava) was obtained from a farmer in a village, Minahasa District, North Sulawesi, Indonesia. Procedures of pretreatmet are as follows: The cassava was peeled and cut into small parts and they were dried under sunlight for days. When dried, cassava was milled until becoming powder using a machine and the particle size was smaller than 100 mesh. Particles were mixed with saline water whose salt concentrations of solution were varied at 3.5 and 10 percent $(\mathrm{w} / \mathrm{w})$. The control was an original substrate, which was not conducted pretreatment. The saline water that was got from sea, has an average salt concentration around 3.5 percent as previously reported (Jakhrani et al. 2012) while, the other solution, which has salt concentration 10 percent (w/w), was prepared by mixing 100 grams commercial salt with 900 grams fresh water.

The pretreatment technique was adapted from some reports using the commercial ionic liquids that were conducted at high temperature (Thomas et al., 2011). Meanwhile, the present study was carried out at low temperatures and used saline solution, which was very cheap. The temperature changed naturally that followed the alteration of room temperature, which varied between $25^{\circ} \mathrm{C}$ and $30^{\circ} \mathrm{C}$ and the process was kept for 5 days. The wash step was applied after pretreatment-treated particles were neutralized by washing with fresh water and then obtained using filter via funnel flask. The recovered solids were dried under sunlight for days until its weight was constant. The treated- and dried solids were weighted and then isolated inside plastic bags prior to characterizations.

The crystallinity change of treated substrates were characterized using XRD (PANalytical, Type: Xpert Pro), FTIR (SHIMADZU, type: IR PRESTIGE 21) and surface morphologies were pictured by SEM (FEI, Type: Inspect S50) and the place of measurement was at State Univ. of Malang East Java. The XRD measurement has started an angle $(2 \theta)$ at $10.01^{\circ}$ and ended at $89.9^{\circ}$ and conducted at $25^{\circ} \mathrm{C}$. The current flowed to the circuit was $35 \mathrm{~mA}$ and voltage difference was of $40 \mathrm{kV}$. The wavelength of K-alpha was of $1.54 \AA$ as K-Beta was set at $1.39 \AA$. While, the wavelength constants used for FTIR characterization were altered from 400 to $4000 / \mathrm{cm}$, which was similar to a previous report (Adebisi et al., 2014). The SEM was employed to understand the change of surface morphology with keeping conditions the following: voltage difference was at $15 \mathrm{kV}$; magnification was of 1000x; WD and spot were set at $10.8 \mathrm{~mm}$ and 5.5, respectively.

The study was to analyze the change of intensity height of $\mathrm{X}$-Ray, which was diffracted for both solids, treated- and native solids. The XRD patterns shown were compared to some reports that related to present work. Meanwhile, the bonds vibrations were analyzed through the fingerprint shown by the FTIR diagram. The variation of transmitted infra-red rays of treated biomass was compared to the original substrate.

\section{Results and discussion}

\subsection{XRD patterns}

Figure 1 shows the XRD pattern of treated substrate and compared to that of original biomass, or without pretreatment. The dominant intensities were located at angles $(2 \theta): 10.99^{\circ}$, $14.59,14.87^{\circ}, 15.17^{\circ}, 16.87^{\circ}, 17.00^{\circ}, 17.98^{\circ}, 18.01^{\circ}, 23.00^{\circ}$, $30.29^{\circ}, 33.00^{\circ}$ and $35^{\circ}$, which were comparable with other reports (Qin et al., 2016).

The XRD pattern of starch, especially its peaks is much more complicated than that of cellulose. Scientists who concentrated on cellulose and starch study found that starch was also more amorphous than cellulosic materials. Authors (Marimuthu et al., 2013) tried to simulate the relation of those angles and reflector planes in (hkl) indices and focused at angles $(2 \theta): 19^{\circ}, 17^{\circ}, 23^{\circ}$ and $30^{\circ}$.

The main peaks of $\mathrm{X}$ ray intensity generated by reflector planes in starch crystal were relatively comparable with those of cellulose. Previous investigations reported that peaks of cellulosic crystal were dominated at 14.26, 16,77, 22.58 and 34.6 as previously published works (Zhao et al., 2012). Meanwhile, the lowest valley that belonged to amorphous parts was at 18.3 (Park et al., 2010). The starch has two highest peaks located at $18^{\circ}$ and $23^{\circ}$, which were a significant difference with a XRD pattern of cellulose that was only one dominant peak at $23^{\circ}$.

The damage of crystallinity of treated cassava starch can be analyzed the decrease of intensity of peak as seen in Table 1. The graph showed that the intensity of diffracted X-Rays significantly declined around $18^{\circ}$, when the substrate was treated by 3.5 - and 10 percents salt of solutions. The peak heights both treated solids were relatively similar at around $18^{\circ}$ but significantly differed at above $23^{\circ}$ in which 10 percents pretreatment was lower than that of 3.5 percents- and original solids. It was also found that the positions of angles $2 \theta$ of treated solid slightly shifted to the right 15.20,17,12 and 18,12 ect from position of original starch as previously described. The space distances of the crystalline cube (d-spacing) of treated solid mostly decreased significantly, which means that the surface area improved. The d-spacing of original biomass were $5.84,5.22,4,93$ and 3.86 compared to those of pretreatment declined to 5.83, 5.18, 4.89 and 3.84. An XRD patterns as previously described shows and proves that the crystallinity of pretreated biomass (cassava) was transformed, or modified compared to that of original solid (Correia et al., 2012; Deka \& Sit, 2016).

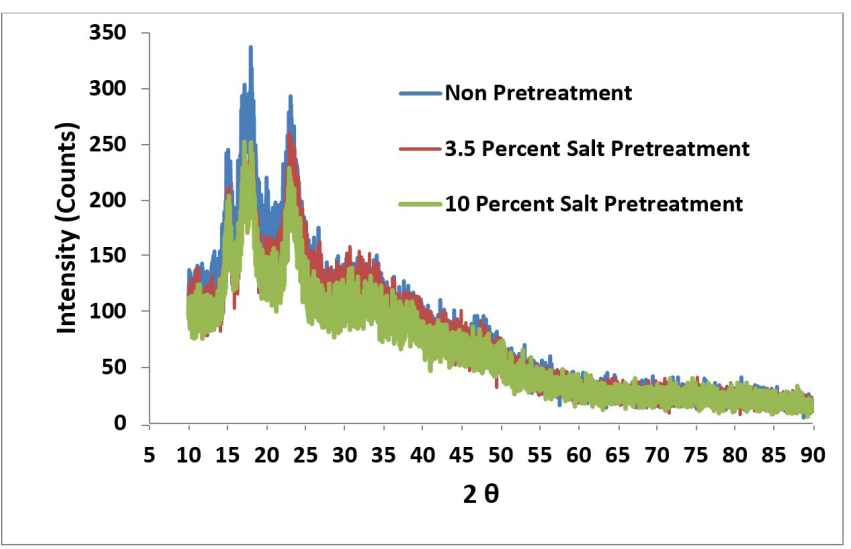

Figure 1. XRD patterns of solid cassava treated by $3.5,10$ percent salts of saline solution (red \& green lines) and compared with non-pretreatment (blue line). 


\subsection{FTIR spectra}

An XRD characterization was compared with FTIR measurement to investigate the solid structures and chemical bonds vibrations. The wavelength constants, $400-4000 / \mathrm{cm}$, were scanned into the sample and those transmitted were analyzed. Figure 2 shows the FTIR spectra of original biomass and treated substrates. These data shows the wavelength constants (some references called vibration frequencies) both substrates but not all absorbance modes were displayed in FTIR fingerprint diagram. The wavelength constants for non-pretreatment are dominated by many numbers as follows (in $1 / \mathrm{cm}$ ): $3053-3600$ represented by $\mathrm{O}-\mathrm{H}$ stretching between polysaccharide connections; 2891.3-2933.73 belonged to C-H symmetrical stretching; 1317 was a bending motion in the plane $\mathrm{CH}, 1014.56$ and 1076 modes were probably the vibrations of $\mathrm{C}-\mathrm{C}$,

Table 1. Intensities of diffracted X-Ray of treated- and control solids at around $2 \theta=18^{\circ}$ plane.

\begin{tabular}{|c|c|c|c|c|c|}
\hline \multicolumn{2}{|c|}{ Native solid } & \multicolumn{2}{|c|}{$3.5 \%$ salt in ionic solution } & \multicolumn{2}{|c|}{$10 \%$ salt in ionic solution } \\
\hline $2 \theta$ & Intensity & $2 \theta$ & Intensity & $2 \theta$ & Intensity \\
\hline 17.81 & 295 & 17.81 & 221 & 17.81 & 227 \\
\hline 17.83 & 248 & 17.83 & 206 & 17.83 & 230 \\
\hline 17.85 & 237 & 17.85 & 194 & 17.85 & 212 \\
\hline 17.87 & 273 & 17.87 & 219 & 17.87 & 209 \\
\hline 17.89 & 292 & 17.89 & 210 & 17.89 & 230 \\
\hline 17.91 & 285 & 17.91 & 202 & 17.91 & 206 \\
\hline 17.93 & 295 & 17.93 & 231 & 17.93 & 227 \\
\hline 17.95 & 282 & 17.95 & 203 & 17.95 & 222 \\
\hline 17.97 & 283 & 17.97 & 198 & 17.97 & 229 \\
\hline 17.99 & 337 & 17.99 & 234 & 17.99 & 220 \\
\hline 18.01 & 286 & 18.01 & 215 & 18.01 & 251 \\
\hline 18.03 & 288 & 18.03 & 216 & 18.03 & 239 \\
\hline 18.05 & 278 & 18.05 & 229 & 18.05 & 215 \\
\hline 18.07 & 279 & 18.07 & 222 & 18.07 & 228 \\
\hline
\end{tabular}

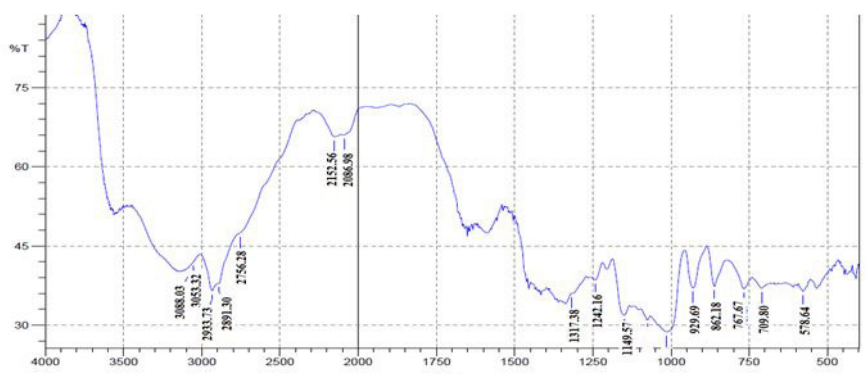

(a)

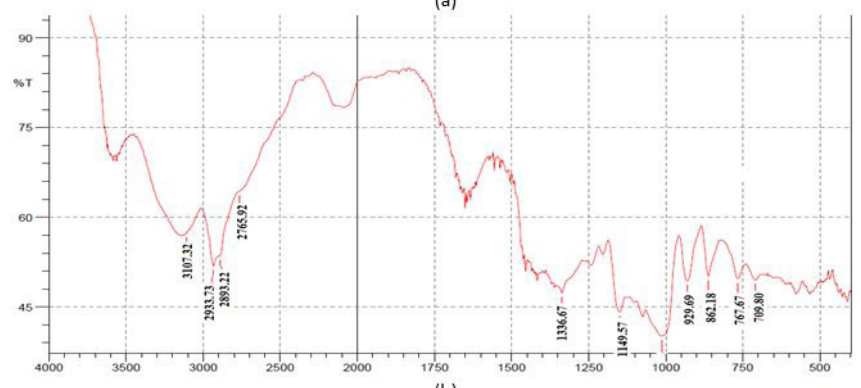

(b)

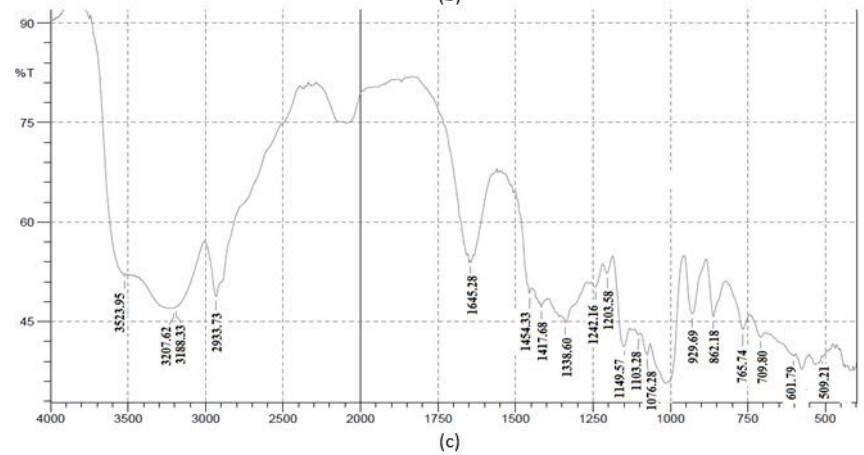

Figure 2. The fingerprints of FTIR spectra of native cassava (a) and 3.5\%- and 10\% salt pretreated substrates (b \& c). 
C-OH, C-H bonds; 862.18 and 929.69 were modes of $\mathrm{C}-\mathrm{O}-\mathrm{C}$, $\mathrm{C}-\mathrm{C}-\mathrm{O}$, and $\mathrm{C}-\mathrm{C}-\mathrm{H}$ stretching motions.

Absorbance's numbers of 1627, 1516 and 1446, which did not display in the finger-print, were bonds motions of as $\mathrm{OH}$ bending vibration of absorbed water, resonant of $\mathrm{C}=\mathrm{C}$ aromatic stretching and $\mathrm{H}-\mathrm{C}-\mathrm{H}$ and $\mathrm{O}-\mathrm{C}-\mathrm{H}$ in-plane bending, respectively, which confirmed investigations from some authors (Correia et al., 2012; Cai et al., 2014; Bajer et al., 2013) and were relatively comparable as previously works for cellulosic biomass (Kumar et al., 2014; Poletto et al., 2014). From data obtained

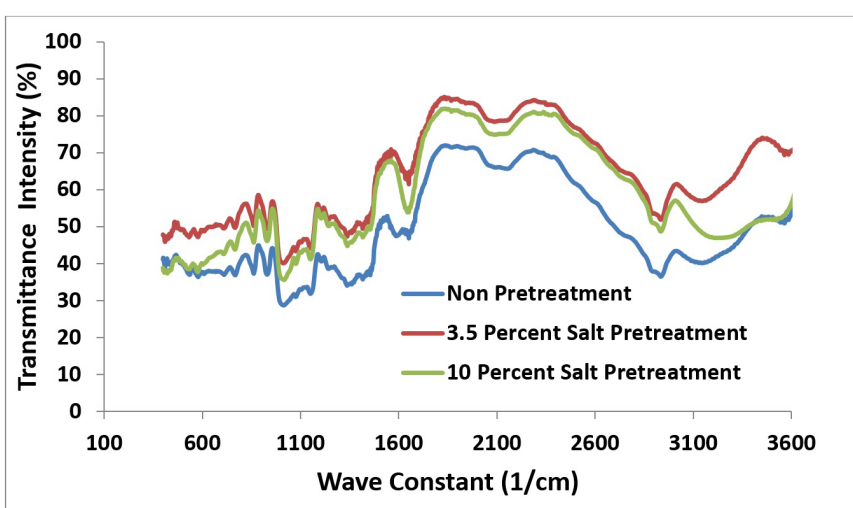

Figure 3. The FTIR fingerprints of cassava powder conducted pretreatment 3.5 percent salt of saline water (red line) and compared with non-pretreatment (blue line). that all measurable quantities, such as intensity, corr. intensity, base $(\mathrm{H})$, base $(\mathrm{L})$, area and corr. area of treated solids changed significantly. The vibration around $1645.2 / \mathrm{cm}$ of treated solids changed significantly, whereby two valleys and one peak appeared for native solid. After pretreatment, the peak totally disappeared from the fingerprint of both samples measured.

As presented in Figure 2, valley and peak around 3623.96/cm occurred an alteration significantly. After 10 percent salt employed, valley and peak were diminished and relatively shifted to the right, whereby the wave constant changed to $3523.95 / \mathrm{m}$. The significant change also occurred at wavelength above $3100 / \mathrm{cm}$, which the infra-red photon transmitted of 10 percent-treated solid declined very much as described in Figure 3. It also added facts that saline water could modify the biomass structure, especially starch that was useful to convert it become more valuable materials, or food. Generally, transmitted infra-red waves through substrates significantly changed for all pretreatments. The intensity heights of infra-red photons transmitted for pretreated biomass were increased that related to many $\mathrm{H}$ bonds were broken down. These were a strong indication the treated substrates were well-modified after pretreatment as shown in Figure 3 which was relatively similar to other reports (Zhang et al., 2014).

\subsection{SEM pictures}

Figure 4 presents the SEM images of starch that was treated by 3.5 and 10 percent of salt and compared with native solid. The samples were shot whose picture was magnified by $1000 \mathrm{x}$

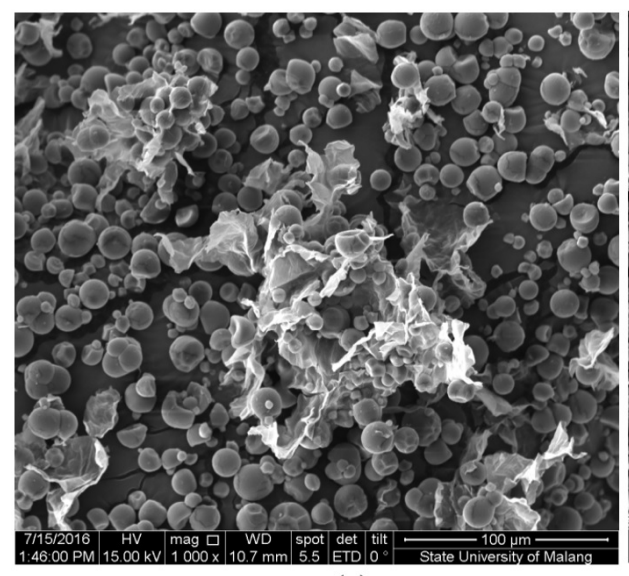

(a)

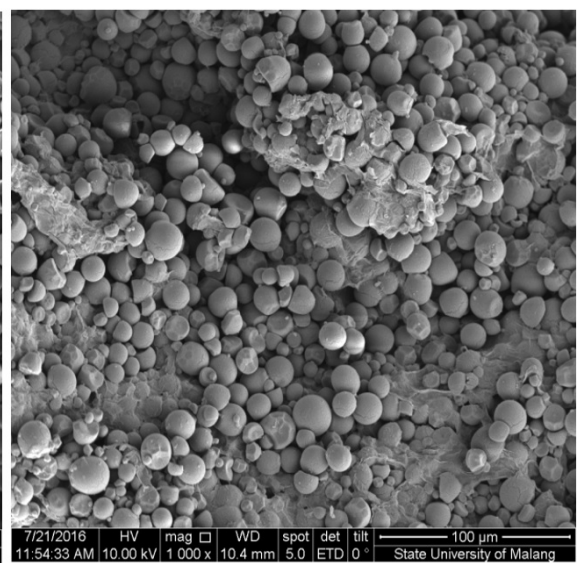

(b)

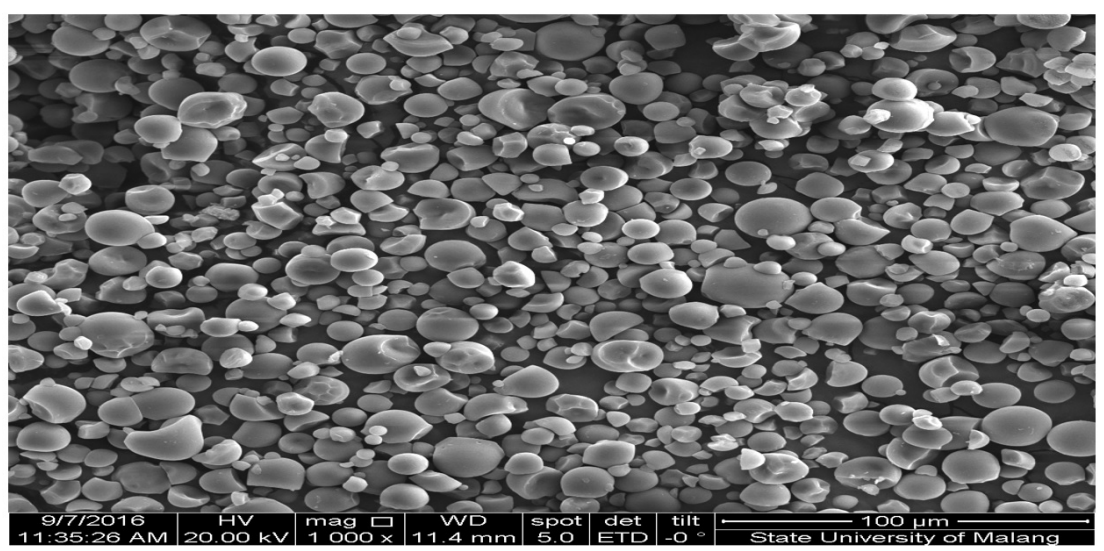

(c)

Figure 4. SEM Pictures of native cassava (a), 3.5\%- and 10\% salt of saline solutions (b \& c) magnified at 1000x. 
as shown in figures. The potential difference applied was altered each sample, whereby $15 \mathrm{kV}$ for native solid, $10 \mathrm{kV}$ for 3.5 percent-pretreated substrates and $20 \mathrm{kV}$ for 10 percent pretreated sample. As shown in figure, the surface morphology of nonpretreatment solid was brighter than that of treated substrates. The shape all particles which were shown has not yet defects and damage. All images exposed that the form of particles are close to round and oval look like, which verified the study conducted previously (Correia et al., 2012).

When the substrate was treated by saline water taken from Manado Beach (concentration 35/1000 of salt), particles shape appeared defective. The surface of the sample was scattered much dust and the picture was blurred because parts of particles were ruined and demolished. For many particles were destroyed becoming dust, their dimensions were reduced significantly so the materials were more porous than that of native solids.

In the middle of round oval particles appeared a formless substance that was likely consisted of other fibers, like cellulose, lignin, and hemicellulose. The surface area of treated substrates significantly improved and was more textured morphology (Utrilla-Coello et al., 2014). The starch that has been modified was not only good for food but also was easily hydrolyzed into reducing sugars using the catalyst as proposed by investigators (da Rosa Zavareze et al., 2010).

When 10 percent salt introduced, the surface became clearer than those of previous pictures. It was indicative that saline agents could dissolve other parts inside biomass, like lignin and hemicellulose. The many oval- and round shapes were damaged significantly and their sizes decreased. There are many small particles, which appears and attaches on the bigger particles (starch). According to shapes and being compared to the reference, those particles were salt dominated by $\mathrm{NaCl}$ that was comparable with work reported previously (Tran et al., 2011). The salt particles attached on starch substances through electrical interaction and bridged between polysaccharide chains. The bonds formed were fiber-OH-Cl-Na-OH-fiber and so on. The dust that showed in Figure $4 \mathrm{~b}$ was removed totally after 10 percent salt was employed for pretreatment. It indicated that higher concentration of salt in saline water could dissolve and cleared of other fibers inside biomass.

\section{Conclusions}

The saline water has been employed to modify the cassava structure that was the most important requirement for textured food, sugar and alcohol productions. If compared with commercial ionic liquids, which was very expensive and poisonous, saline water was free, abundant and enviromnentally-friendly. The disadvantage for using this new solvent was the pretreatment was conducted for 5 days. However, it was compensated by zero energy usage since pretreatment process was not powered by electricity.

\section{References}

Adebisi, F., Adedaya, A., Oluwaseye, A., Adekunle, F., Michael, A., Olutayo, O., Clement, A., Ikokoh, P., Rasheed, K., \& Ademola, A. (2014). Instrumental and chemical characterization of moringa oleifera lam root starch as an industrial biomaterial. Research in Pharmaceutical Biotechnology, 5(1), 7-12.

Alcazàr-Alay, S. C., \& Meireles, M. A. A. (2015). Physicochemical properties, modification and application of starches from different botanical sources. Food Science and Technology, 35(2), 215-236. http://dx.doi.org/10.1590/1678-457X.6749.

Bajer, D., Kaczmarek, H., \& Bajer, K. (2013). The structure and properties of different types of starch exposed toUV radiation: a comparative study. Carbohydrate Polymers, 98(1), 477-482. http:// dx.doi.org/10.1016/j.carbpol.2013.05.090. PMid:23987371.

Cai, J., Cai, C., Man, J., Yang, Y., Zhang, F., \& Wei, C. (2014). Crystalline and structural properties of acid-modified lotus rhizome C-type starch. Carbohydrate Polymers, 102, 799-807. http://dx.doi.org/10.1016/j. carbpol.2013.10.088. PMid:24507349.

Correia, P., Cruz-Lopes, L., \& Beirão-da-Costa, L. (2012). Morphology and structure of chestnut starch isolated by alkali and enzymatic methods. Food Hydrocolloids, 28(2), 313-319. http://dx.doi. org/10.1016/j.foodhyd.2011.12.013.

Deka, D., \& Sit, N. (2016). Dual modification of taro starch by microwave and other heatmoisture treatments. International Journal of Biological Macromolecules, 92, 416-422. http://dx.doi.org/10.1016/j. ijbiomac.2016.07.040. PMid:27423413.

Gunawan, S., Widjaja, T., Zullaikah, S., Ernawati, L., Istianah, N., Aparamarta, H. W., \& Prasetyoko, D. (2015). Effect of fermenting cassava with Lactobacillus plantarum, Saccharomyces cereviseae, and Rhizopus oryzae on the chemical composition of their flour. International Food Research Journal, 22(3), 1280-1287.

Hernoux, A., Lévêque, J. M., Lassi, U., Molina-Boisseau, S., \& Marais, M. F. (2013). Conversion of a non-water soluble potato starch waste into reducing sugars under non-conventional technologies. Carbohydrate Polymers, 92(2), 2065-2074. http://dx.doi.org/10.1016/j. carbpol.2012.11.048. PMid:23399259.

Jakhrani, A. Q., Samo, S. R., Sobuz, H. R., Uddin, M. A., Ahsan, M. J., \& Hasan, N. M. S. (2012). Assessment of Dissolved Salts Concentration of Seawater in the Vicinity of Karachi. International Journal of Structural and Civil Engineering, 1(2), 61-69.

Kumar, A., Negi, Y. S., Choudhary, V., \& Bhardwaj, N. K. (2014). Characterization of cellulose nanocrystals produced by acid-hydrolysis from sugarcane bagasse as agro-waste. Journal of Materials Physics and Chemistry, 2(1), 1-8.

Lopez, Y., Gullon, B., Puls, J., Parajo, J. C., \& Martin, C. (2011). Dilute acid pretreatment of starch-containing rice hulls for ethanol production. Holzforschung, 65(4), 467-473. http://dx.doi.org/10.1515/hf.2011.082.

Manzanares, P., Ballesteros, I., Negro, M. J., Oliva, J. M., Gonzalez, A., \& Ballesteros, M. (2012). Biological conversion of forage sorghum biomass to ethanol by steam explosion pretreatment and simultaneous hydrolysis and fermentation at high solid content. Biomass Conversion and Biorefinery, 2(2), 123-132. http://dx.doi. org/10.1007/s13399-012-0040-8.

Marimuthu, M., Venkatesh, M., \& Poongodi, M. (2013). X-ray diffraction analysis of nano sized seed powder of white colored germplasm of velvet bean (Mucuna pruriens), an underutilized wild south indian food legume. Nano Biomedicine and Engineering, 5(3), 121-126. http://dx.doi.org/10.5101/nbe.v5i3.p121-126.

Nafchi, A. M., Alias, A. K., Mahmud, S., \& Robal, M. (2012). Antimicrobial, rheological, and physicochemical properties of sago starch films filled with nanorod-rich zinc oxide. Journal of Food Engineering, 113(4), 511-519. http://dx.doi.org/10.1016/j.jfoodeng.2012.07.017. 
Neelam, K., Vijay, S., \& Lalit, S. (2012). Various techniques for the modification of starch and the applications of its derivatives. International Research Journal of Pharmacy, 3(5), 25-31.

Park, S., Baker, J. O., Himmel, M. E., Parilla, P. A., \& Johnson, D. K. (2010). Cellulose crystallinity index: measurement techniques and their impact on interpreting cellulase performance. Biotechnology for Biofuels, 3(1), 1-10. http://dx.doi.org/10.1186/1754-6834-3-10. PMid:20497524.

Pereira, B. L. B., \& Leonel, M. (2014). Resistant starch in cassava products. Food Science and Technology, 34(2), 298-302. http://dx.doi. org/10.1590/fst.2014.0039.

Poletto, M., Ornaghi, H. L. Jr., \& Zattera, A. J. (2014). Native Cellulose: Structure, Characterization and Thermal Properties. Materials, 7(9), 6105-6119. http://dx.doi.org/10.3390/ma7096105. PMid:28788179.

Puncha-Arnon, S., \& Uttapap, D. (2013). Rice starch vs. rice flour: Differences in their properties when modified by heat-moisture treatment. Carbohydrate Polymers, 91(1), 85-91. http://dx.doi. org/10.1016/j.carbpol.2012.08.006. PMid:23044108.

Qin, Y., Liu, C., Jiang, S., Xiong, L., \& Sun, Q. (2016). Characterization of starch nanoparticles prepared by nanoprecipitation: Influence of amylose content and starch type. Industrial Crops and Products, 87, 182-190. http://dx.doi.org/10.1016/j.indcrop.2016.04.038.

Sangian, H. F., Ranggina D., Ginting, G. M., Purba, A. A., Gunawan, S., Widjaja, A. (2015). Study of the preparation of sugar from highlignin lignocellulose applying subcritical water and enzymatic hydrolysis: synthesis and consumable cost evaluation. Scientific Study \& Research Chemistry \& Chemical Engineering, Biotechnology, Food Industry, 16(1), 13-27.

Silva, E. C., Sobrinho, V. D. S., \& Cereda, M. P. (2013). Stability of cassava flour-based food bars. Food Science and Technology, 33(1), 192-198. http://dx.doi.org/10.1590/S0101-20612013005000025.

Souto, L. R. F., Caliari, M., Soares, M. S. Jr., Fiorda, F. A., \& Garcia, M. C. (2016). Utilization of residu from cassava starch processing for fermentable sugar by enzymatic hydrolysis. Food Science and Technology, 37(1), 19-24. http://dx.doi.org/10.1590/1678-457x.0023.

Souza, T. A. C., Soares Júnior, M., Campos, M. R. H., Souza, T. S. C., \& Bandeira, L. C. (2013). The effect of chemical treatments on the $\mathrm{pH} \&$ microbial flora of cassava residues during storage. Food Science and Technology, 33(3), 457-462. http://dx.doi.org/10.1590/ S0101-20612013005000070.

Thomas, M. F., Li, L.-L., Handley-Pendleton, J. M., van der Lelie, D., Dunn, J. J., \& Wishart, J. F. (2011). Enzyme activity in dialkyl phosphate ionic liquids. Bioresource Technology, 102(24), 11200-11203. http:// dx.doi.org/10.1016/j.biortech.2011.09.069. PMid:22001053.

Tran, R. T., Naseri, E., Kolasnikov, A., Bai, X., \& Yang, J. (2011). A new generation of sodium chloride porogen for tissue engineering. Biotechnology and Applied Biochemistry, 58(5), 335-344. http:// dx.doi.org/10.1002/bab.44. PMid:21995536.

Utrilla-Coello, R. G., Hernández-Jaimes, C., Carrillo-Navas, H., González, F., Rodríguez, E., Bello-Pérez, L. E., Vernon-Carter, E. J., \& Alvarez-Ramirez, J. (2014). Acid hydrolysis of native corn starch: Morphology, crystallinity, rheological and thermal properties. Carbohydrate Polymers, 103, 596-602. http://dx.doi.org/10.1016/j. carbpol.2014.01.046. PMid:24528771.

Yakubov, G. E., Zhong, L., Li, M., Boehm, M. W., Xie, F., Beattie, D. A., Halley, P. J., \& Stokes, J. R. (2015). Lubrication of starch in ionic liquid-water mixtures: Solublecarbohydrate polymers form a boundary film on hydrophobic surfaces. Carbohydrate Polymers, 133, 507-516. http://dx.doi.org/10.1016/j.carbpol.2015.06.087. PMid:26344308.

Zavareze, E. R., Storck, C. R., Castro, L. A. S., Schirmer, M. A., \& Dias, A. R. G., Rosa Zavareze, E., Storck, C. R., Castro, L. A. S., Schirmer, M. A., \& Dias, A. R. G. (2010). Effect of heat-moisture treatment on rice starch of varying amylose content. Food Chemistry, 121(2), 358-365. http://dx.doi.org/10.1016/j.foodchem.2009.12.036.

Zhang, J., Fang, Z., Deng, H., Zhang, X., \& Bao, J. (2013). Cost analysis of cassava cellulose utilization scenarios for ethanol production on flowsheet simulation platform. Bioresource Technology, 134, 298-306. http://dx.doi.org/10.1016/j.biortech.2013.02.041. PMid:23500588.

Zhang, Y., Zeng, H., Wang, Y., Zeng, S., \& Zheng, B. (2014). Structural characteristics and crystalline properties of lotus seed resistant starch and its prebiotic effects. Food Chemistry, 155, 311-318. http://dx.doi. org/10.1016/j.foodchem.2014.01.036. PMid:24594190.

Zhao, D., Li, H., Zhang, J., Fu, L., Liu, M., Fu, J., \& Ren, P. (2012). Dissolution of cellulose in phosphate-based ionic liquids. Carbohydrate Polymers, 87(2), 1490-1494. http://dx.doi.org/10.1016/j.carbpol.2011.09.045. 